Svitlana Tkalenko, D.Sc. in Economics, Associate Professor of the Department of European Economics and Business, Kyiv National Economic University named after Vadym Hetman (Kyiv, Ukraine)

\title{
MODEL OF INVESTMENT SECURITY OF THE NATIONAL ECONOMY IN THE CONDITIONS OF DIGITALIZATION: CASE OF UKRAINE
}

\begin{abstract}
The current stage of world development leads to global challenges facing the countries of the world, in particular, it concerns the ensuring economic security and its component - investment. The current stage of ensuring the security of national economies has led to the transformation of this concept. The change of the paradigm of economic security has led to an increase in the role of investment security and its further research. External and internal factors, processes and their interconnections, lack of sufficient information, digitalization determine the characteristics of the model and the complexity of the study of this issue. The article focuses on the role and approach to the study of investment security; the author constructed a cognitive map of factors characterizing the interconnection of investment security elements. The map of the investment security model is disclosed through the stages of its formation, namely object analysis, cognitive analysis, building a cognitive model, building a cognitive map, as well as determining (detecting) its vertices and the relationships of factors characterizing investment security. It has determined positive and negative influence of factors that change depending on the current conditions of development of the world economy and the development of information and communication technologies.
\end{abstract}

Keywords: investment security, investment climate, digitalization, positive image, investment activity

Introduction. World events and economic development trends show the dynamics of the development of information and communication technologies, which means the need for transformations of the national economies of the world. Transformational and modernization changes lead to increased relevance and research to ensure the security of national economies and the formation of appropriate models. Globalization and digitalization significantly change the views on the security problem. Understanding the relevance and need to consider economic security and its component, namely investment security to ensure sustainable economic growth, there is no clear answer today to address these problematic issues in the 
world. This is due to exogenous factors, security risks, which can and should be considered, but it is impossible to take them all into account.

At the same time, not all issues of investment security in the current conditions of development of national economies are reflected in the scientific literature. Therefore, in this regard, this issue is relevant and requires further study.

The purpose of the research is to investigate features and characteristics of the formation of the model of investment security due to modern conditions of world economic development.

Methodological basis of the research. The research is based on the theoretical and methodological material of the study of investment security. The author investigates this issue on the basis of cognitive modelling, in particular, a map of the investment security model is constructed, certain vertices of the cognitive map and their interconnections and mutual influences characterizing investment security are identified.

\section{A paradigmatic multistructural model of investment security of the national} economy. In the context of geopolitical changes, the focus is on the «new» concept of «economic security», which increasingly emphasizes the risk of unexpected shocks and economic volatility, and it is a multi-factor category. A more detailed study of its component, namely investment security from the aggregated new definition of the concept of «economic security» will contribute to the achievement of the multiplier effect of ensuring economic security in general.

Contemporary development, which is characterized by asymmetry, unevenness, a paradigm change in economic security, has led to the emergence of a rational approach to the study of this issue, where attention is given to new security sectors, such as financial, investment and others. The correlation between security sectors and levels of rational approach is shown in table 1 . 
Table 1

Correlation between sectors and levels (rational approach)

\begin{tabular}{|c|c|c|c|c|c|c|c|c|}
\hline \multirow{2}{*}{ Level } & \multicolumn{7}{|c|}{ Security sectors } \\
\cline { 2 - 10 } & Political & Military & Economic & Financial & Investment & Ecological & Technological & $\ldots . .$. \\
\hline Global & $\mathrm{Mn}$ & $\mathrm{N}$ & $\mathrm{N}$ & $\mathrm{N}$ & $\mathrm{N}$ & $\mathrm{D}$ & $\mathrm{D}$ & $?$ \\
\hline$\ldots \ldots \ldots \ldots$. & $?$ & $?$ & $?$ & $?$ & $?$ & $?$ & $?$ & $?$ \\
\hline Regional & $\mathrm{Md}$ & $\mathrm{Md}$ & $\mathrm{Mn}$ & $\mathrm{Mn}$ & $\mathrm{Mn}$ & $\mathrm{Mn}$ & $\mathrm{Md}$ & $?$ \\
\hline$\ldots \ldots \ldots \ldots \ldots$ & $?$ & $?$ & $?$ & $?$ & $?$ & $?$ & $?$ & $?$ \\
\hline National & $\mathrm{D}$ & $\mathrm{D}$ & $\mathrm{D}$ & $\mathrm{D}$ & $\mathrm{D}$ & $\mathrm{D}$ & $\mathrm{D}$ & $?$ \\
\hline Individual & $\mathrm{N}$ & $\mathrm{N}$ & $\mathrm{N}$ & $\mathrm{N}$ & $\mathrm{N}$ & $\mathrm{N}$ & $\mathrm{N}$ & $?$ \\
\hline
\end{tabular}

$\mathrm{D}-\overline{\text { dominant correlation, } \mathrm{Md}}-$ moderate correlation, $\mathrm{Mn}-$ insignificant correlation, and $\mathrm{N}-$ no correlation

Source: finalized by the author on the basis of data [1]

Investment security is being investigated in leading countries of the world, in particular in the USA, Canada, Germany, Great Britain etc. In these countries, the relevant structures determine the list of critical objects for ensuring investment security. These are usually systems and assets, including both physical and virtual forms, which are vital for countries $[2,3,4,5,6 ; 7,8]$.

Investment security is such a state of the national economy, which is characterized by economic growth in terms of security development and provides guarantees for the protection of the rights of foreign investors and includes all the institutions of the investment system. The latter provide an innovative type of organization, effective management of investment resources, at which the multiplier and accelerative effects of investment are achieved in order to ensure a socially oriented sustainable and competitive development of the national economy. The multiplier effect is realized through investing in the national economy and the implementation of indirect influence on other sectors of the economy as structural elements. The accelerating effect is manifested in the long run due to the influence of other sectors of the economy on the basic industry, where it attracted capital expenditure, that led to a chain reaction.

Investment security reflects the set of elements, namely goals, interests of entities (individuals, states, societies), the risks and threats that affect them, which is a multi-factor model. According to the mathematical point of view, it is quite difficult to calculate how the activity or inactivity of the entity will affect the investment security system as a whole. The complexity of the study of the investment security model of the national economy is attributable to:

- the multifactorial processes and their relationships; 
- the lack of sufficient quantitative information of the dynamics of processes, that forces us to move to a qualitative analysis of processes;

- the variability and speed of changes in processes over time, etc.

Cognitive modelling of investment security system. Digitalization is of enormous importance in the current context of the world economy, which contributes to the creation of the latest information and communication technologies, new products and it creates new needs on the market. Investment flows are diverted to new digital technologies. We propose to use the cognitive method, which consists of constructing and analyzing a cognitive map of the situation, considering such features for systematizing the elements of investment security and for modelling such systems. The construction of a cognitive map of the investment security model of the national economy is considered through the following stages:

The first stage is to analyze the object. At this stage, the modelling object should be surveyed and examined. The structure of the model and the connection between the external and internal environment should be analyzed. We form requirements for the created model, methods and technologies of work and tools for creating the model.

The second stage is to conduct the cognitive analysis. We formulate the tasks and define the purposes of research; we analyze the situation from the standpoint of the goal; we systematize the quantitative and qualitative characteristics of our model; and we identify the main features of the studied process, its characteristics and find out the connections between them. Then, we formulate the actions of the main objective laws of development related to the situation. We consider such laws in various fields, in particular in the political, economic, social, ecological, etc., which will allow us to analyze existing trends and to identify objective dependencies while conducting this analysis.

The third stage is the construction of a cognitive model, where the factors that characterize this situation are highlighted; we discover the basic factors (which are the vertices); we select the target factors in the aggregation of basic factors; we determine the controlling factors that influence the target (these factors are the input and coordinating signals of the impact on the situation); we determine the factors and indicators that reflect and explain the development of processes in this situation and their impact on various areas.

The fourth stage is the construction of a cognitive map. The vertices of the cognitive map mutually and unambiguously correspond to the basic factors of the situation in which processes are described; direct relationships between factors are determined by considering causal relationships in chains describing the influence of one factor on other factors. 
The influence of factors can be either reinforcing (positive), or inhibiting (negative), or even of a variable sign depending on possible additional conditions.

The cognitive map shows us the influence of one factor on another. It does not reflect the dynamics of changes in the effects of factors depending on changes in the situation, nor does it show the detailed nature of these effects, and it does not show temporary changes in the factors themselves. So, taking this situation into account requires a transition to the next level of structuring of winning information, which is reflected on the cognitive map, and means a direct relationship to the cognitive model. At this level, all the relationships between the factors on the cognitive map are revealed in accordance with the equation. The latter contains variables in qualitative and quantitative measurements.

Thus, the cognitive map is a subjective model of the reproduction of a particular problem situation by means of which it is possible to understand certain patterns of the model. Cognitive maps are graph methods designed to formalize the description of a complex object, problem, the functioning of the system, models and the identification of cause-and-effect relationships between their elements. Causal relationship through a cognitive map can be represented as:

$$
G=<E, W>
$$

where,

$E=\left\{e_{1}, e_{2}, \ldots e_{n-1}, e_{n}\right\}-$ the multiplicity of factors affecting investment security;

$E_{i} \in E, i=1,2, \ldots k,-$ elements of the system that is being investigated;

$W$ - binary relations on a set $E$, which specifies a set of relationships between its elements. $W$ - plural arcs, arcs $w_{i j} \in W$, and $, j=1,2, \ldots N$ show the relationship between the vertices $E_{i}$ and $E_{j}$, and their influence on each other.

The cognitive map $\mathrm{G}$ can be represented by a matrix of relations $A_{G}$. The matrix $A_{G}$ is a square matrix, the rows and columns of which are marked by the vertices of the graph $G$, and at the intersection of the $i$ row, the $j$ column (or not) of the unit, if there is (or does not exist) a relationship between elements $E_{i}$ and $E_{j}$, namely:

$$
A_{j}=\left[a_{i j}\right]_{k \times k}, a_{i j}=\left\{\begin{array}{cc}
1 & \text { if } E_{i} \text { belongs to } E_{j} \\
0 & \text { otherwise }
\end{array}\right.
$$

The ratio $e_{i j}$ can take values between « $+1 »$ and «-1». The relationship is characterized by «+1» in the case of a positive impact, «-1» in the case of a negative impact, and $0-$ in the absence of interaction between the elements. This matrix of interactions of factors is given in table 2 . 
The relationships shown in table 2 are explained as follows: the safety of the investment security model (E1) is positively affected by the favourable investment climate in the state; a positive image of the state, in particular, is formed on the basis of general indices according to the rating of countries that affect the investment decision-making process; a favourable investment infrastructure will facilitate the flow of investment resources and the development of business infrastructure; providing guarantees to foreign investors, which is a civilized practice of providing protection to foreign investments in case of changes in legislation, against illegal actions of authorities, etc.; incentive measures for investments are manifested, for example, in the form of benefits to encourage investments to the national economy, etc.; the state activity in the field of investment activity (attracting FDI), in particular, through the public sector of the economy, as well as through executive authorities, the National Bank, etc.

Table 2

Cognitive map vertices and their interrelationships and the mutual influence of factors characterizing investment security

\begin{tabular}{|c|c|c|c|c|c|c|c|c|c|c|c|}
\hline Vertex & Influencing factor & \multicolumn{7}{|c|}{ Factors that are affected } \\
\cline { 4 - 12 } & elements & $\mathrm{E}_{1}$ & $\mathrm{E}_{2}$ & $\mathrm{E}_{3}$ & $\mathrm{E}_{4}$ & $\mathrm{E}_{5}$ & $\mathrm{E}_{6}$ & $\mathrm{E}_{7}$ & $\mathrm{E}_{8}$ & $\mathrm{E}_{9}$ & $\mathrm{E}_{10}$ \\
\hline $\mathrm{E}_{1}$ & $\begin{array}{c}\text { Safety of investment security } \\
\text { model }\end{array}$ & $\mathrm{x}$ & 0 & +1 & 0 & 0 & 0 & 0 & 0 & 0 & 0 \\
\hline $\mathrm{E}_{2}$ & Inefficiency of legal support & -1 & $\mathrm{x}$ & 0 & 0 & 0 & -1 & 0 & 0 & 0 & 0 \\
\hline $\mathrm{E}_{3}$ & $\begin{array}{c}\text { Favourable investment } \\
\text { climate }\end{array}$ & +1 & 0 & $\mathrm{x}$ & 0 & +1 & 0 & 0 & 0 & 0 & 0 \\
\hline $\mathrm{E}_{4}$ & $\begin{array}{c}\text { Lack of certainty of priority } \\
\text { investment sectors }\end{array}$ & -1 & 0 & -1 & $\mathrm{x}$ & 0 & 0 & 0 & 0 & 0 & 0 \\
\hline $\mathrm{E}_{5}$ & $\begin{array}{c}\text { Positive image of the state } \\
\text { Favorable investment } \\
\text { infrastructure }\end{array}$ & +1 & 0 & 0 & 0 & $\mathrm{x}$ & 0 & +1 & 0 & +1 & 0 \\
\hline $\mathrm{E}_{6}$ & $\begin{array}{c}\text { Providing guarantees to } \\
\text { foreign investors }\end{array}$ & +1 & +1 & +1 & 0 & 0 & +1 & $\mathrm{x}$ & 0 & 0 & 0 \\
\hline $\mathrm{E}_{7}$ & $\begin{array}{c}\text { Investment incentives } \\
\mathrm{E}_{8}\end{array}$ & +1 & 0 & +1 & 0 & 0 & +1 & 0 & $\mathrm{x}$ & 0 & 0 \\
\hline $\mathrm{E}_{9}$ & $\begin{array}{c}\text { State activity in the field of } \\
\text { investment activity } \\
\text { (attracting FDI) }\end{array}$ & +1 & +1 & +1 & +1 & 0 & 0 & 0 & +1 & $\mathrm{x}$ & +1 \\
\hline $\mathrm{E}_{10}$ & $\begin{array}{c}\text { Lack of monitoring and } \\
\text { regulation of the investment } \\
\text { process }\end{array}$ & -1 & 0 & 0 & 0 & -1 & 0 & 0 & -1 & 0 & $\mathrm{X}$ \\
\hline
\end{tabular}

Source: [9] 
A negative impact on the safety of the investment security model is provided by the inefficiency of legal support; the lack of certainty of priority investment sectors (foreign investors commonly invest in those sectors of the economy where it is faster to make a profit); the lack of monitoring and regulation of the investment process.

Strengthening and improving the effectiveness of legal support (E2) is affected by the provision of guarantees to foreign investors, measures to stimulate investment, and primarily the state's activity in the field of investment activity.

The formation of the favourable investment climate (E3) is affected by the safe state of the investment security model; positive image of the state at the global level; providing guarantees to foreign investors; investment incentive measures; the government activity in the field of investment and the possibility of attracting FDI. The lack of certainty of priority investment sectors hinders the formation of the favorable investment climate.

The lack of certainty of priority investment sectors (E4) can be eliminated through government activity in the field of investment.

The favourable investment climate and the favourable investment infrastructure will contribute to the formation of a positive image of the state (E5). The lack of monitoring and regulation of the investment process will hinder the formation of the positive image of the state.

The formation of a favourable investment infrastructure (E6) is influenced by the provision of guarantees to foreign investors and measures to stimulate investment. The ineffectiveness of legal support has a negative impact on it.

The positive image of the state contributes to the strengthening of guarantees to foreign investors (E7).

The state's activity enhances stimulating measures in investment activity (E8), and the lack of monitoring and regulation of the investment process restrains such measures.

The positive image strengthens the activity of the state in the field of investment activity (E9).

The lack of monitoring and regulation of the investment process (E10) can be eliminated by means of the government activity.

The relationship between the identified factors that characterize the investment security strategy can be depicted using the cognitive map presented in Fig. 1. 


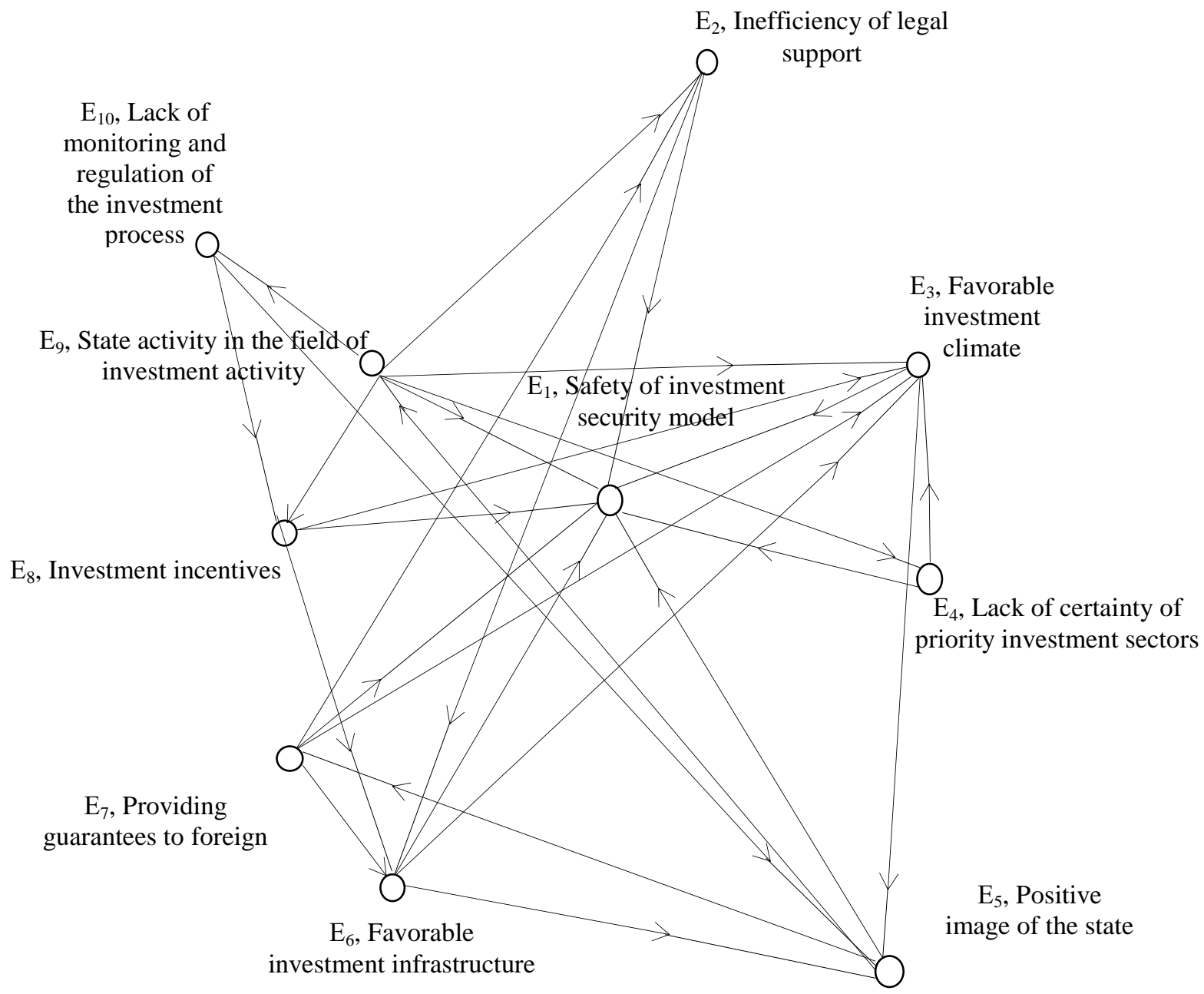

Figure 1. Cognitive map of factors that characterizes the relationship of elements of investment security

Source: [9]

The analysis of the investment security model of the national economy allows us to distinguish basic target factors and control factors characterizing investment security (presented in table 2). The basic target factors of the investment security model system include its safety (E1) and the formation of the favourable investment climate (E3). Governing factors include the factor of the government activity in the field of investment activity (E9), the lack of certainty of priority investment sectors (E4) and the lack of monitoring and regulation of the investment process (E10).

In conclusion, we note that the model of investment security strategy of the national economy as a combination of it with significant ties is multistructural. The multistructural model of the investment security strategy is a complex, heterogeneous system, which has its own subsystems and it is defined by the axioms. 
Conclusions. The investment security model is characterized by a paradigm associated with the movement of foreign investment, the provision of measures to counter risks and threats in the investment sphere and the formation of the investment security model. The current stage is characterized by a rational approach in the research methodology of this issue. It has been possible to identify such different security sectors and establish a correlation between them and the levels (global, regional, national and individual); the dominant correlation exists precisely between the investment security sector at the national level. The paradigm of investment security caused by the conditions of globalization and digitalization of the current stage of development of national economies, as well as the need for modernization and transformation.

Cognitive modelling, cognitive analysis and the construction of a cognitive map made it possible to systematize the elements of investment security characterizing their relationship on the basis of evaluating and analyzing their impact on the security level and providing description of the current state of the situation. The cognitive map is a subjective model of reproducing problem situations by means of certain patterns of a model which are fully understood. The modeling method uses a scenario method that combines qualitative and quantitative criteria for solving static and dynamic problems that consider the current state of economic development and the environment of investment activity, developing and making effective decisions that open up opportunities for creating an effective investment security model with a sufficient degree of reality for adoption the most optimal solutions. The constructed model includes such factors as the safety of the investment security model, the inefficiency of legal support, a favorable investment climate, the lack of certainty of priority investment sectors, a positive image of the state, a favorable investment infrastructure, the provision of guarantees to foreign investors, investment incentives, and state activity in the field of investment activity (attracting FDI), lack of monitoring and regulation of the investment process.

Thus, in the context of digitalization, attention should be given to creating a cognitive map of factors that will allow more effectively to formulate a model of investment security of the country at each new stage of economic development. 


\section{References}

1. Mieczyslaw Malec (2003). Security perception: within and beyond the traditional approach. Naval Postgraduate School, June, 91 p.

2. U.S. Department of the Treasury. URL: www.treasury.gov/about/organizationalstructure

3. Australia: «What is critical infrastructure?» (2007) Australian National Security. URL: www.ag.gov.au/agd

4. Canada: About Critical Infrastructure (2008). Public Safety Canada. URL: www.ps-sp.gc.ca

5. Germany: Critical Infrastructure Protection in Germany. Federal Office for Information Security. URL: www.bsi.de/english/topics/kritis/ KRITIS_in_Germany.pdf

6. Netherlands Report on Critical Infrastructure protection; Ministry of the Interior (2005).

7. United Kingdom Home Office Security. Counter Terrorism Strategy: Protecting the Critical National Infrastructure. URL: www.security.homeoffice.gov.uk

8. United States: Department of Homeland «National Infrastructure Protection Plan» (2006). URL: www.dhs.gov

9. Ткаленко С. I. (2018) Інвестиційна безпека: теорія, методологія, практика: монографія. Чернігів: ЧНТУ. 286 с. 